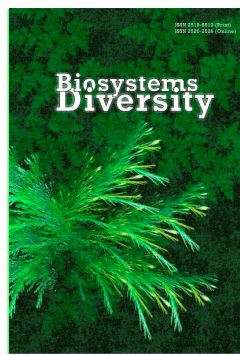

\title{
Analysis of the productivity of pine stands in plantations in the Northern Steppe of Ukraine
}

\author{
V. M. Lovynska, S. A. Sytnyk, K. P. Maslikova, Y. I. Gritsan \\ Dnipropetrovsk State Agrarian and Economic University, Dnipro, Ukraine
}

Article info

Received 25.12.2016

Received in revised form 08.02.2017

Accepted 12.02.2017

Dnipropetrovsk State Agrarian and Economic University, Ephremov Str., 25,

Dnipro, 49600, Ukraine

Tel.: +38-066-559-54-63

E-mail: glub@ukr.net
Lovynska, V. M., Sytnyk, S. A., Maslikova, K. P., \& Gritsan, Y. I. (2017). Analysis of the productivity of pine stands in plantations in the Northern Steppe of Ukraine. Biosystems Diversity, 25(1), 39-43. doi: 10.15421/011706

The aim of this work is the comparative analysis of the productivity of Scots pines in pure and mixed plantations with main and accompanying species in the Northern Steppe of Ukraine We analysed the taxation parameters such as height, diameter, stand density, which vary with the age of the stand and composition of the plantation. Within the study area pines grow mainly in pure stands $(81.9 \%)$. The share of mixed forest stands in the study area is only $18.1 \%$. The analysis of representation of age structure showed the presence of the same proportion of the young age group in pure and mixed stands, the dominant share being taken up by middle-aged monoculture stands, and thus a smaller area taken up by mature and overmature pines. The average stand density per 1 ha in pure stands of all age groups is $17 \%$ higher than in mixed stands. The dynamics of variations of such biometric data as average height, diameter and density for the different compositions of Scots pine stands were measured for 14 age classes. The mean heights of the pure and mixed stands are vere close, while the average diameter gradually increased with age, reaching its maximum in overmature plantations. The research results showed that there is an excess of this parameter in the mixed compared with the pure stands. We did not find significant differences between middle age pure and mixed stands in accumulation of stand density. But pure pine stands show a clear tendency to dominate in wood accumulation in all age classes through the period of growth. The greatest difference between pure and mixed stands in the mean stand density was observed for those of middle-age. The average stand density in the pure stands was up to $32 \%$ higher than the mixed. The area distribution of Scots pine stands according to productivity was as follows. The largest area for both pure and mixed stands was occupied by trees of quality class I, which took up $54.3 \%$ of the total pure pine acreage and $41.9 \%$ of the mixed stand acreage. The second position was occupied by quality class II, which occupied $27.6 \%$ of total pure pine acreage and $36.6 \%$ of mixed stand acreage with the perecentage of total stand density at $23.6 \%$ and $35.1 \%$ respectively. In general, the value of the average stand density falls as the quality class decreases, and essentially depends on the composition of plantations: in pure stands, it is higher than in mixed. The investigated values of the biometric parameters are statistically significant for both the pure and the mixed stands.

Keywords: Pinus sylvestris L.; Northern Steppe of Ukraine; stand density; pure and mixed stands

\section{Особенности продуктивности сосновых древостоев в лесонасаждениях Северной Степи Украины}

\author{
В. Н. Ловинская, С. А. Сытник, К. П. Масликова, Ю. И. Грицан \\ Днепропетровский государственный аграрно-экономический университет, Днепр, Украина
}

Проанализирована возрастная структура древостоев сосны обыкновенной (Pinus sylvestris L.) в чистых и смешанных лесонасаждениях Северной Степи Украины. Показано превалирование доли средневозрастных монокультур сосны. Средний запас древесины на 1 га во всех исследуемых возрастных группах однопородных насаждений превышает таковой в смешанных максимум на $17 \%$. Приведена динамика изменений биометрических показателей (высоты, диаметра и запаса древесины) для разных по составу сосновых насаждений. По сравнению со средней высотой, показатель средного диаметра имеет большую зависимость от возраста, что особенно характерно для древостоев смешанного типа. Наблюдается тенденция доминирования формирования древесины в чистых по составу насаждениях во всех исследуемых классах возраста на 3-32 \%. Показано уменьшение величины среднего запаса по мере снижения бонитетного класса, которое в чистых насаждениях выше сравнительно со смешанными. Приведены статистически достоверные значения зависимости таксационных параметров древостоев от возраста, как в чистых, так и смешанных насаждениях.

Ключевые слова: Pinus sylvestris L.; Северная Степь Украины; запас древесины; чистые и смешанные насаждения

\section{Введение}

Организация и ведение комплексного лесного хозяйства Украины требуют новых подходов к оценке биологической продуктивности и пополнению ее систематизированными показателями биологической продуктивности главных лесообразующих пород (Lakyda, 2003; Dufrene et al., 2005). Оценка состояния и уровня ведения лесного хозяйства в разных реги- 
онах Украины позволит определить экологические и экономические аспекты устойчивого развития лесонасаждений (Sidelnik, 1977; Chumachenko et al., 2003; Furdichko et al., 2006).

При облесении зоны степей в их жестких лесорастительных условиях с преобладанием на большей части площадей очень сухих и сухих боров одной из главных лесообразующих пород является сосна обыкновенная (Pinus sylvestris L.). Как свидетельствуют литературные данные, первые географические культуры сосны обыкновенной в степной зоне были заложены в 1963 г. лесничим А. Я. Якобсоном под руководством В. Н. Виноградова в кварталах опытного лесничества Нижнеднепровской научно-исследовательской базы облесения песков (Kilimchuk and Korobov, 1993).

До сегодняшнего времени сосна обыкновенная является одним из наиболее важных видов лесных насаджений Степи, и в частности, Северной байрачной Степи Украины, не только в связи c ее широким здесь распространением, но и благодаря высоким экологическим и социально-экономическим ценностям (Bulakhov and Pakhomov, 2010; Moroz et al., 2011; Rio et al., 2013; Brygadyrenko, 2014, 2016; Toigo et al., 2015; Tsvetkova et al., 2016).

В последнее время возрасла важность исследований чистых и смешанных насаджений и вопросы сравнения их продуктивности уже давно составляют особую сферу интересов в лесной науке, хотя в целом отсутствуют общие подходы к изучению этой проблематики (Ketly et al., 1992; Balandier et al., 2000; Schmid and Kazda, 2002; Piotto, 2008; Pretzsch et al., 2010; Brassard et al., 2011; Aakala et al., 2013; Maire et al., 2013; Forrester, 2014b, 2015; Pretzsch et al., 2015, 2016).

Сосна обыкновенная образует на территории Северной Степи как чистые, так и смешанные насаждения с другими главными и второстепенными породами леса. Именно сравнительный анализ их продуктивности был основной целью данной работы.

\section{Материал и методы исследований}

Объект исследований - основная лесообразующая хвойная порода Северной Степи - сосна обыкновенная (аборигенный вид), доля которой в насаждениях данного региона составляет 24,6\% площади, покрытой лесом (Hulchak, 2011). Как первичную учетно-фондовую информацию использовали повыдель- ную базу данных земель лесного фонда ВО «Укргослеспроект» чистых и смешанных древостоев сосны обыкновенной Днепропетровской области в количестве 5158 таксационных выделов, общей площадью 21 472,9 га (табл. 1). Для каждого таксационного выдела определены площадь выдела, состав насаждения, его возраст, бонитет, средние высота, диаметр, запас на 1 га. При распределении древостоев на чистые и смешанные к чистым относили насаждения с участием сосны обыкновенной с коэффициентом состава данной породы 10 единиц, к смешанным - древостои с участием сосны обыкновенной в составе насаждений 9 единиц и меньше.

Результаты исследований статистически обработаны и представлены с помощью Statistica 12.0 (StatSoft Inc., USA). На графиках показаны зависимости таксационных параметров от возраста древостоев и их различия в зависимости от состава насаждения (чистого и смешанного типа). Вертикальные линии на кривых графиков обозначают среднеквадратическое отклонение. Различия между значениями исследуемых таксационных характеристик считали достоверными при $\mathrm{P}<0,05$.

\section{Результаты}

Сосна обыкновенная представлена в исследуемом регионе преимущественно чистыми (17578 га, 81,9\%), или смешанными насаждениями с незначительной примесью других древесных пород, таких как акация белая, ясень обыкновенный, шелковица черная, клен полевой и т. д. (3894,9 га, 18,1%). Сравнение биометрических показателей таксационных характеристик отдельных возрастных групп чистых и смешанных сосновых древостоев Северной Степи приведены в таблице 2. Чистые и смешанные древостои сосны обыкновенной в соответствии с их возрастными группами имеют определенные различия по показателям распределения площадей, общему и среднему запасам древесины. Анализ представленности возрастных групп показал наличие одинаковых долей чистых и смешанных молодняков, превалирование доли средневозрастных древостоев монокультур и, соответственно, менышее количество сосняков приспелого и спелого возрастов. Во всех возрастных группах значения среднего запаса выше для однопородных насаждений. Средневзвешенная величина запаса древесины на 1 га в чистых насаждениях превышает таковую в смешанных на 17 \%.

\section{Таблица 1}

Характеристика района исследований

\begin{tabular}{|c|c|c|c|c|c|c|c|c|c|c|c|c|c|c|c|c|}
\hline \multirow{3}{*}{$\begin{array}{c}\text { Состав } \\
\text { насаждений }\end{array}$} & \multicolumn{16}{|c|}{ Лесхозы } \\
\hline & \multicolumn{2}{|c|}{ Васильковский } & \multicolumn{2}{|c|}{$\begin{array}{c}\text { Верхнеднепров- } \\
\text { ский }\end{array}$} & \multicolumn{2}{|c|}{$\begin{array}{c}\text { Днепродзер- } \\
\text { жинский }\end{array}$} & \multicolumn{2}{|c|}{$\begin{array}{l}\text { Днепропетров- } \\
\text { ский }\end{array}$} & \multicolumn{2}{|c|}{$\begin{array}{c}\text { Новомосковский } \\
\text { военный }\end{array}$} & \multicolumn{2}{|c|}{$\begin{array}{l}\text { Новомосков- } \\
\text { ский } \\
\end{array}$} & \multicolumn{2}{|c|}{ Павлоградский } & \multicolumn{2}{|c|}{$\begin{array}{l}\text { Днепровско- } \\
\text { Орельский }\end{array}$} \\
\hline & выдел & $\mathrm{S}$, га & выдел & $\mathrm{S}$, га & выдел & $\mathrm{S}$, га & выдел & $\mathrm{S}$, га & выдел & $\mathrm{S}$, га & выдел & $\mathrm{S}$, га & выдел & $\mathrm{S}$, га & выдел & $\mathrm{S}$, га \\
\hline Чистые & 240 & 1377,8 & 38 & 148,6 & 921 & 5333,8 & 174 & 970,5 & 2017 & 4929,4 & 281 & 1589,7 & 373 & 2582,6 & 97 & 289,0 \\
\hline мешанные & 68 & 343,0 & 25 & 87,1 & 171 & 1102,1 & 37 & 151,4 & 515 & 1706,8 & 52 & 224,7 & 13 & 69,3 & 21 & 147,6 \\
\hline
\end{tabular}

Таблица 2

Возрастная структура древостоев сосны обыкновенной

\begin{tabular}{|c|c|c|c|c|c|c|c|c|c|c|}
\hline \multirow{3}{*}{ Возрастные группы } & \multicolumn{4}{|c|}{ Площадь } & \multicolumn{4}{|c|}{ Запас } & \multicolumn{2}{|c|}{ Средний запас, м³/га } \\
\hline & \multicolumn{2}{|c|}{ чистые } & \multicolumn{2}{|c|}{ смешанные } & \multicolumn{2}{|c|}{ чистые } & \multicolumn{2}{|c|}{ смешанные } & \multirow{2}{*}{ чистые } & \multirow{2}{*}{ смешанные } \\
\hline & га & $\%$ & га & $\%$ & тыс. $\mathrm{M}^{3}$ & $\%$ & тыс. $\mathrm{M}^{3}$ & $\%$ & & \\
\hline Молодняки & 5743,4 & 32,7 & 1293,7 & 33,2 & 700,9 & 17,3 & 67,3 & 12,9 & 130 & 69 \\
\hline Средне-возрастные & 10680,8 & 60,8 & 1876,0 & 48,2 & 3013,2 & 74,4 & 340,5 & 65,2 & 284 & 239 \\
\hline Приспелые & 845,2 & 4,8 & 499,4 & 12,8 & 259,3 & 6,4 & 82,5 & 15,8 & 297 & 234 \\
\hline Спелые & 307,6 & 1,7 & 220,4 & 5,7 & 75,4 & 1,9 & 30,7 & 5,9 & 232 & 207 \\
\hline Переспелые & 1,0 & 0,0 & 5,4 & 0,1 & 0,2 & 0,0 & 1,0 & 0,2 & 226 & 225 \\
\hline Всего & 17578,0 & 100,0 & 3894,9 & 100,0 & 4049,0 & 100,0 & 522,0 & 100,0 & 234 & 195 \\
\hline
\end{tabular}

Проведенный анализ таксационных характеристик возрастных групп предоставил возможность оценить значимость разницы между общими показателями, но не позволил установить динамические изменения в соотвествии с возрастом. Поэтому мы сочли нужным проанализировать динамику средних значений таксационных характеристик - средних высот, диаметра и запаса древесины для разных по составу древостоев сосны обыкновенной по классам возраста, который составляет 10 лет (рис. 1-3). Возрастная амплитуда как чистых, так и

смешанных древостоев охватывает 14 классов. Как показали результаты исследований, четкой тенденции однозначных изменений величин средней высоты сосновых древостоев не наблюдалось (рис. 1). Значения средних высот чистых и смешанных древостоев очень близки, и лишь в 7, 8, 11 и 13-м классах возраста фиксируется незначительная дисперсия исследуемой величины.

Динамика показателей среднего диаметра имеет несколько иную тенденцию по сравнению с высотой, что и демонстри- 
рует рисунок 2. Средний диаметр имеет существенную зависимость от возраста и постепенно увеличивается, достигая своего максимума в более старших насаждениях. По данным рисунка можно также проследить превышение данного пара- метра в смешанных насаждениях по сравнению с чистыми, до 12-го класса возраста, и только в группе спелых и переспелых насаждений (12-14-й классы возраста) наблюдается обратная зависимость.

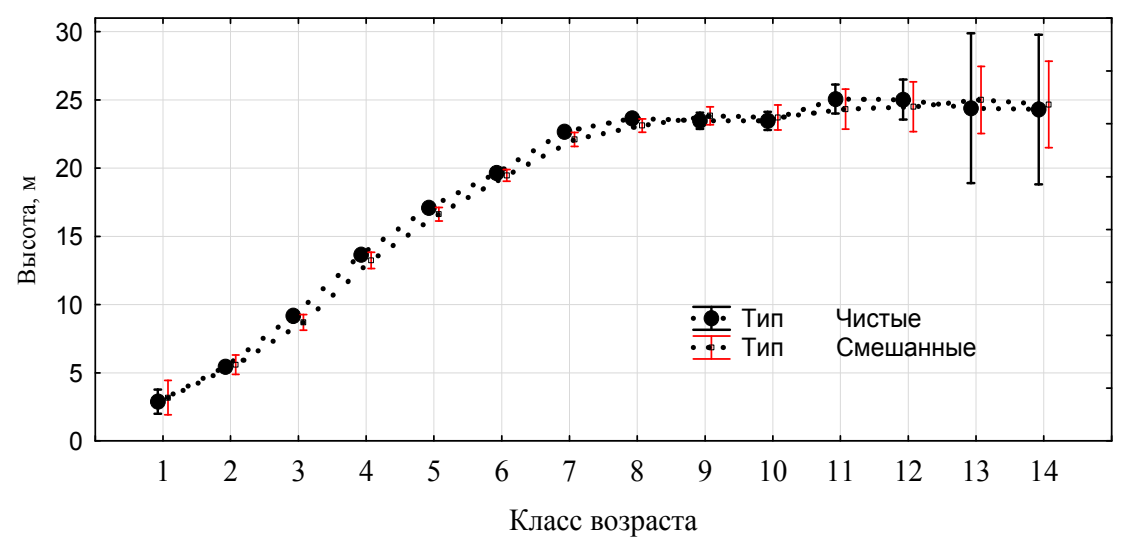

Рис. 1. Зависимость высоты чистых и смешанных сосновых древостоев от класса возраста $(\mathrm{n}=30)$

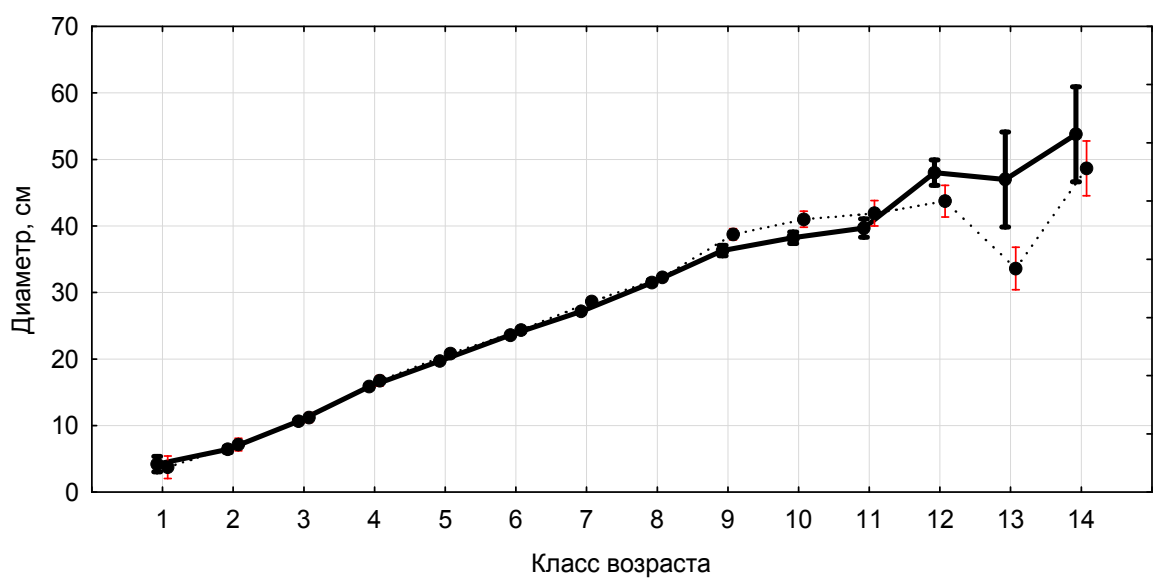

Pис. 2. Зависимость диаметра чистых и смешанных сосновых древостоев от класса возраста $(\mathrm{n}=30)$

Приведенные диаграммы средних высот и диаметров лишь частично подтверждают постулат о зависимости продуктивности древостоев от данных величин. Продуктивность древостоя - это прежде всего количественная характеристика - запас древостоя, который измеряется объемом древесной массы, образующейся за единицу времени. В насаждениях сосны особенно существенной разницы между трендами накопления средних запасов древесины в чистых и смешанных насаждениях не обнаружено. Однако между исследуемыми группами наблюдается четкая тенденция доминирования накопления древесины в чистых древостоях сосны в течение всего периода времени от 1 до 14-го классов возраста, с максимальным разрывом между показателями в средневозрастных насаждениях сосны.
Средний запас древесины сосны обыкновенной чистых древостоев превышает соответствующие показатели смешанных минимум на 3\% (14-й класс), максимум - на 32\% (3-й класс возраста) (рис. 3). В 12-м классе возраста этот показатель равен для разных по составу насаждений. Также определены аналитические зависимости между исследованными таксационными показателями (средние высоты, диаметры, запасы) от класса возраста в чистых и смешанных насаждениях (табл. 3). Как видно из представленного анализа, зависимости исследуемых параметров являются достоверными, как в случае чистых, так и смешанных насаждений.

Неоднозначность динамики исследованных таксационных параметров подтверждена данными по бонитетной характеристике сосняков (табл. 4).

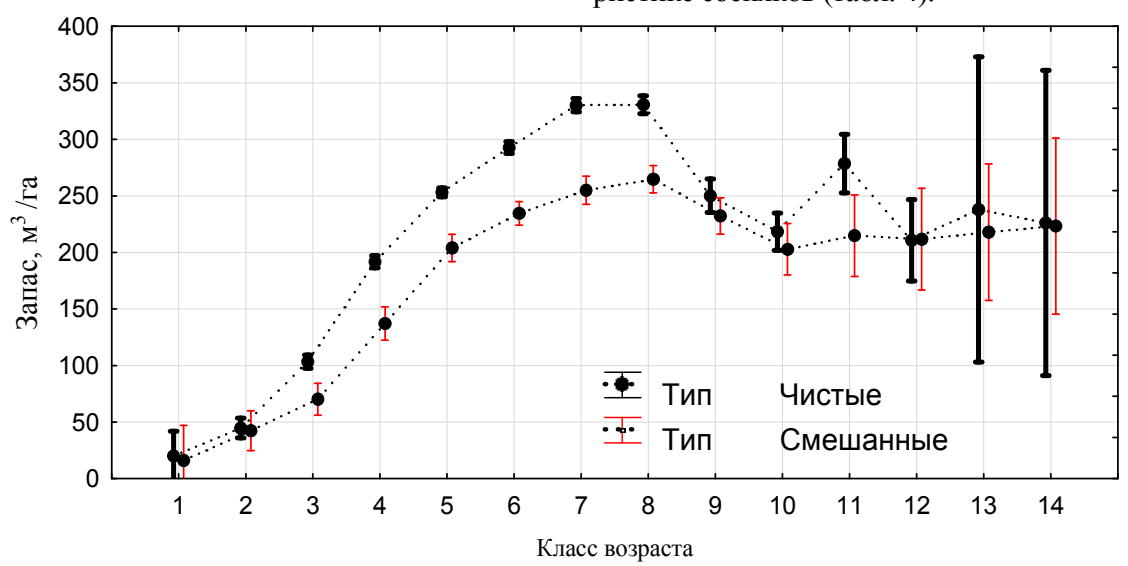

Рис. 3. Зависимость среднего запаса чистых и смешанных сосновых древостоев от класса возраста $(\mathrm{n}=30)$ 
Таблица 3

Зависимость основных таксационных показателей древостоя от возраста в чистых и смешанных сосновых лесонасаждениях

\begin{tabular}{lccc}
\hline \multicolumn{1}{c}{ Показатель } & \multicolumn{2}{c}{ Чистые насаждения } & \multicolumn{2}{c}{ Смешанные насаждения } \\
\cline { 2 - 4 } \multicolumn{1}{c}{ Сравнение } & коэффициент детерминации & уравнение & коэффициент детерминации \\
\hline Средний диаметр & $d=3,594 a^{0,831}$ & $\mathrm{R}^{2}=0,93$ & $\mathrm{R}^{2}=0,94$ \\
Средняя высота & $h=3,908 a^{0,989}$ & $\mathrm{R}^{2}=0,99$ & $h=4,029 a^{0,816}$ \\
Средний запас на 1 га & $M=34,335 a^{0,905}$ & $\mathrm{R}^{2}=0,74$ & $M=25,540 a^{0,972}$ \\
\hline
\end{tabular}

Таблица 4

Распределение площади и запаса древостоев сосны обыкновенной по классам бонитета

\begin{tabular}{|c|c|c|c|c|c|c|c|c|c|c|}
\hline \multirow{3}{*}{ Класс бонитета } & \multicolumn{4}{|c|}{ Площадь } & \multicolumn{4}{|c|}{ Запас } & \multicolumn{2}{|c|}{ Средний запас, м $^{3} / г a$} \\
\hline & \multicolumn{2}{|c|}{ чистые } & \multicolumn{2}{|c|}{ смешанные } & \multicolumn{2}{|c|}{ чистые } & \multicolumn{2}{|c|}{ смешанные } & \multirow{2}{*}{ чистые } & \multirow{2}{*}{ смешанные } \\
\hline & га & $\%$ & га & $\%$ & тыс. $\mathrm{M}^{3}$ & $\%$ & тыс. $\mathrm{M}^{3}$ & $\%$ & & \\
\hline І и выше & 9551,6 & 54,3 & 1631,4 & 41,9 & 2746,7 & 67,8 & 286,6 & 54,9 & 285 & 235 \\
\hline II & 4842,9 & 27,6 & 1426,6 & 36,6 & 954,6 & 23,6 & 183,3 & 35,1 & 191 & 184 \\
\hline III & 2521,0 & 14,3 & 612,8 & 15,7 & 306,9 & 7,6 & 46,1 & 8,8 & 117 & 106 \\
\hline IV & 534,6 & 3,1 & 199,9 & 5,2 & 36,5 & 0,9 & 5,7 & 1,1 & 64 & 46 \\
\hline V и ниже & 127,9 & 0,7 & 24,2 & 0,6 & 4,4 & 0,1 & 0,3 & 0,1 & 40 & 20 \\
\hline Всего & 17578,0 & 100,0 & 3894,9 & 100,0 & 4049,0 & 100,0 & 522,0 & 100,0 & 140 & 118 \\
\hline
\end{tabular}

Распределение площади сосны обыкновенной по классам бонитета выглядело следующим образом: в большем количестве как чистые, так и смешанные насаждения сосны обыкновенной растут по I классу бонитета, доля которых в исследуемом регионе составляет $54,3 \%$ и $41,9 \%$ соответственно. Вторую позицию по распространенности занимают древостои II класса, доли которых в насаждениях чистого и смешанного состава равны $27,6 \%$ и $36,6 \%$, с соответствующими запасами древесины $23,6 \%$ и $35,1 \%$. На древостои, растущие по III классу бонитета, приходятся почти равные части площадей в сопоставимых по составу насаждениях, а на низкобонитетные - лишь незначительная часть сосняков, как в случае однопородных (3,7\%), так и смешанных (5,7\%).

Приведенные данные подтверждают постулат о зависимости продуктивности древостоев от класса бонитета. Как видим, величина среднего запаса падает по мере снижения класса бонитета и существенным образом зависит от состава насаждений: в чистых древостоях она выше, чем в смешанных.

\section{Обсуждение}

В первые годы формирования древесного полога, как в смешанных, так и в чистых насаждениях происходит четкая дифференциация деревьев по высоте, диаметру, кроне, которая связана с освоением деревьями свободного пространства (Barthélémy and Caraglio, 2007). Такое перераспределение наблюдается изначально в почвогрунте и осуществляется корневыми системами, а после - достигается путем расхождения крон по горизонтали и вертикали в надземном пространстве (Danjon et al., 2005; Pretzsch et al., 2016). При формировании сосновых насаждений во втором - третьем десятилетии их жизненного цикла происходит возвышение и разрастание одних, сжатие и вытеснение из общего полога других деревьев, которые совершаются за счет перераспределения занятого ими пространства, в том числе вытеснения части деревьев в нижний ярус и дальнейшее их угнетение.

При формировании смешанных насаждений нарастает ажурность полога верхнего яруса и усиливается развитие подъяруса за счет обилия сопутствующих пород, произрастающих в таких условиях по IV классу роста. В этих условиях снижается рост и одной из главных лесообразующих пород для Северной Степи - сосны обыкновенной. В связи с этим являются необходимыми своевременные прореживания той или иной интенсивности с целью обеспечения своевременного перераспределения пространства для крон основной части древостоя и предупреждения формирования деревьев с искривленными стволами (Webster and Lorimer, 2003).

В данной работе представлены результаты анализа таксационных показателей (высоты, диаметра, запаса стволов деревьев), изменяющихся с возрастом древостоя в зависимости

от состава насаждений - смешения пород и роста монокультур. Зависимости, найденные для указанных параметров в ходе роста, показывают максимальное продуцирование древесной массы для чистых по составу насаждений. Результаты вариабельности высот и их зависимости от возраста являются наиболее неточными и не отличаются в насаждениях как чистого, так и смешанного типа.

Pretzsch et al. (2015), Pretzsch and Schutze (2016) провели широкомасштабные исследования в нескольких странах Европы (от Швеции до Болгарии и от Испании до Украины), направленные на изучение и сравнение структуры, динамики и продуктивности главных лесообразующих пород, включая и P.sylvestris, в основном для 60-80-летних деревьев, формирующих чистые и смешанные насаждения. В смешанных древостоях авторы наблюдали интенсификацию роста сосны обыкновенной, не зависящей от класса бонитета, роста насаждения в целом, а также климатических переменных.

О более высокой продуктивности сосны в смешанных насаждениях сравнительно с монокультурами говорят и данные, приведенные Shanin et al. (2014). Показатель формирования биомассы, по мнению авторов, в значительной степени зависит от плодородия почв участков, а также от составляющих видов древостоя. Накопление максимального количества чистой первичной продукции и углерода в фитомассе наблюдалось для древостоев, состоящих из хвойных пород P. sylvestris L. и Picea abies L., а также при введении в насаждение лиственной Betula pendula Roth.

В соответствии с результатами зарубежных авторов, смешанные культуры часто дают более высокий показатель производительности биомассы древесных пород, что прежде всего отображается на превышающем приросте модельных деревьев, по сравнению с чистыми насаждениями. Rio and Sterba (2009), рассматривая формирование прироста в чистых и смешанных насаждениях P. sylvestris и Quercus pyrenaica L. указывают на более высокий показатель формирования объема древесины на единицу площади в смешанных насаждениях, чем в соответствующих монокультурах этих видов. Среди возможных причин снижения конкуренции в смешанных насаждениях минимизация межвидовой борьбы в надземном пологе является одним из главных факторов, который рассмотрен в указанной работе. Наши данные отличаются от результатов приведенных авторов и свидетельствуют о более высоких показателях продуктивности деревьев сосны обыкновенной в условиях создания монокультур в нашем регионе. Это согласуется с данными Frivold and Frank (2002), которые, изучая смешанный тип насаждения сосны и березы, не увидели существенного положительного эффекта данной композиции. Rothe and Binkley (2001), изучая трофические взаимодействия в смешанных лесах, выявили различные ответы в зависимости от видов и факторов влияния окружающей среды. 
Относительно же продуктивности древостоев, исследования, направленные на расчеты данного показателя в насаждениях разного типа, выявили противоречивые результаты, что прежде всего связано с составляющими насаждения видами, а также условиями их местопроизрастания. Rio and Sterba (2009) отмечают, что, хотя темпы роста отдельно каждого древесного вида выше в смешанных насаждениях, общий их прирост в таких условиях ниже по сравнению с чистыми сосняками. Этот факт объясняется гораздо большей продуктивностью одного вида в чистых древостоях (Ketly, 1992). В этом случае, как утверждают авторы, различия в приросте очень велики, следовательно, уменьшение площади, доступной для сосны обыкновенной, не компенсируется за счет увеличения роста входящих в состав насаждения видов, формирующих смешанный древостой.

В целом, данные изучения сосновых древостоев в условиях формирования чистых и, особенно, смешанных насаждений, позволяют сделать заключение о необходимости проведения рубок ухода в данном регионе, а также их усиления в большинстве случаев, что приведет к активизации направленного регулирования развития древостоев и интенсификации их выращивания. Очевидно, что вопросы продуктивности чистых и смешанных насаждений главных лесообразующих пород в условиях Степи требуют дальнейших исследований.

\section{Выводы}

По средней высоте древостоя исследуемые лесонасаждения сосны обыкновенной почти не отличаются. Как в чистых, так и в смешанных насаждениях с возрастом фиксируется рост средней высоты с максимальным значением 25,5 м для 13-го класса возраста. Средний диаметр чистых насаждений меньше такового в смешанных до 12-го класса возраста, после чего прослеживается обратная зависимость. По средним запасам древесины наблюдается существенная разница между исследуемыми группами насаждений с доминированием однопородных, вплоть до 14-го класса возраста. У молодых и средневозрастных насаждениях фиксируется преобладание данной величины в чистых древостоях в большей степени, по сравнению с экземплярами старшего возраста.

\section{References}

Aakala, T., Fraver, S., D’Amato, A., \& Brian, J. (2013). Influence of competition and age on tree growth in structurally complex old-growth forests in northern Minnesota, USA. Forest Ecology and Management, 308, 128-135.

Balandier, P., Lacointe, A., Le Roux, X., Sinoquet, H., Cruiziat, P., \& Le Dizes, S. (2000). SIMWAL: A structural-functional model simulating single walnut tree growth in response to climate and pruning. Annals of Forest Science, 57(5), 571-585.

Barthélémy, D., \& Caraglio, Y. (2007). Plant architecture: A dynamic, multilevel and comprehensive approach to plant form, structure and ontogeny. Annals of Botany, 99, 375-407.

Brassard, B. W., Chen, H. Y. H., Bergeron, Y., \& Paré, D. (2011). Differences in the fine root productivity between mixed- and singlespecies stands. Functional Ecology, 25, 238-246.

Brygadyrenko, V. V. (2014). Influence of soil moisture on litter invertebrate community structure of pine forests of the steppe zone of Ukraine. Folia Oecologica, 41(1), 8-16.

Brygadyrenko, V. V. (2016). Effect of canopy density on litter invertebrate community structure in pine forests. Ekológia (Bratislava), 35(1), 90-102.

Bulakhov, V. L., \& Pakhomov, O. Y. (2010). Funkcional'na zoologija [Functional zoology]. Dnipropetrovsk University Press, Dnipropetrovsk (in Ukrainian).

Chumachenko, S. I., Korotkov, V. N., Palenova, M. M., \& Politov, D. V. (2003). Simulation modelling of long-term stand dynamics at different scenarios of forest management for coniferous-broad-leaved forests. Ecological Modelling, 170(2-3), 345-361.

Danjon, F., Fourcaud, T., Bert, D. (2005). Root architecture and windfirmness of mature Pinus pinaster Ait. New Phytologist, 168, 387-400.

Dufrene, E., Davi, H., Francois, C., Le Mare, G., Le Dantec, V., \& Granier, A. (2005). Modelling carbon and water cycles in a beech forest. Part I:
Model description and uncertainty analysis on modelled NEE. Ecological Modelling, 185(2-4), 407-436.

Forrester, D. I. (2014). The spatial and temporal dynamics of species interactions in mixed-species forests: From pattern to process. Forest Ecology and Management, 312, 282-292.

Forrester, D. I. (2015). Transpiration and water-use efficiency in mixedspecies forests versus monocultures: Effects of tree size, stand density and season. Tree Physiology, 35, 289-304.

Furdichko, O. I., Gladun, G. B., \& Lavrov, V. V., 2006. Lis u Stepu: Osnovi stalogo rozvitku [Forest in the Steppe: The basics of sustainable development]. Osnova, Kiyv (in Ukrainian).

Hulchak, V. P. (ed.) (2011). Osnovni polozhennja organizacii' i rozvytku lisovogo gospodarstva Dnipropetrovs'koi' oblasti [The main provisions of forest organization and management of Dnipropetrovsk region]. Irpin, Dnipropetrovsk (in Ukrainian).

Kelty, M. J. (1992). Comparative productivity of monocultures and mixed species stands. In: Kelty, M. J., Larson, B. C., \& Oliver, C. D. (Eds.). The ecology and silviculture of mixed-species forests. Kluwer Academic Publishers, Dordrecht, $125-141$.

Kilimchuk, N. D., \& Korobov, I. A. (1983). Geograficheskie kul'tury sosny obyknovennoj na nizhnedneprovskih peskah [Geographic culture of Scots pine on the lower Dnieper sands]. Lesovedenie i Agrolesomelioracija, 65, 29-32 (in Russian).

Lakyda, P. I. (2003). Fitomasa lisiv Ukrainy [Phytomass of Ukrainian forests]. Sbruch, Ternopil (in Ukrainian).

Linden, M., \& Agestam, E. (2003). Increment and yield in mixed and monoculture stands of Pinus sylvestris and Picea abies based on an experiment in Southern Sweden. Scandinavian Journal of Forest Research, $18,155-162$.

Maire, G., Nouvellon, Y., Christina, M., Ponzoni, F. J., Gonc, J. L. M., Bouillet, J. P., \& Laclau, J. P. (2013). Tree and stand light use efficiencies over a full rotation of single- and mixed-species Eucalyptus grandis and Acacia mangium plantations. Forest Ecology and Management, 288, 31-42.

Moroz, K. O., Brygadyrenko, V. V., \& Pakhomov, A. Y. (2011). Formirovanije fauny napochvennykh bespozvonochnykh peschanoj terrasy r. Orel' $v$ uslovijakh pirogennoj sukcessii [Litter invertebrates fauna formation of the sandy terrace of Orel' river in condition of post-fire succession]. Proceedings of the Azerbaijan Society of Zoology, 3, 423-435 (in Russian).

Piotto, D. (2008). A meta-analysis comparing tree growth in monocultures and mixed plantations. Forest Ecology and Management, 255, 781-786.

Pretzsch, H., Bauerle, T., Häberle, K. H., Matyssek, R., Schütze, G., \& Rötzer, T. (2016). Tree diameter growth after root trenching in a mature mixed stand of Norway spruce (Picea abies [L.] Karst) and European beech (Fagus sylvatica [L.]). Trees, 30(5), 1761-1773.

Pretzsch, H., Block, J., Dieler, J., Dong, P. H., Kohnle, U., Nagel, J., Spellmann, H., \& Zingg, A. (2010). Comparison between the productivity of pure and mixed stands of Norway spruce and European beech along an ecological gradient. Annals of Forest Science, 67, 1-12.

Pretzsch, H., Forresterb, D., \& Rötzer, T. (2015). Representation of species mixing in forest growth models. Ecological Modelling, 313, 276-292.

Pretzsch, H., del Río, M., Ammer, C., Avdagic, A., Barbeito, I., Bielak, K., Brazaitis, G., Coll, L., Dirnberger, G., Drössler, L., Fabrika, M., Forrester, D. I., Godvod, K., Heym, M., Hurt, V., Kurylyak, V., Löf, M., Lombardi, F., Matović, B., Mohren, F., Motta, R., den Ouden, J., Pach, M., Ponette, Q., Schütze, G., Schweig, J., Skrzyszewski, J., Sramek, V., Sterba, H., Stojanović, D., Svoboda, M., Vanhellemont, M., Verheyen, K., Wellhausen, K., Zlatanov, T., \& Bravo-Oviedo, A. (2015). Growth and yield of mixed versus pure stands of Scots pine (Pinus sylvestris L.) and European beech (Fagus sylvatica L.) analysed along a productivity gradient through Europe. European Journal of Forest Research, 134(5), 927-947.

Pretzsch, H., \& Schütze, G. (2016). Effect of tree species mixing on the size structure, density, and yield of forest stands. European Journal of Forest Research, 135(1), 1-22.

Rio, M., Condes, S., \& Sterba, H. (2013). Mixing effect on volume growth of Fagus sylvatica and Pinus sylvestris is modulated by stand density. Forest Ecology and Management, 292, 86-95.

Rio, M., \& Sterba, H. (2009). Comparing volume growth in pure and mixed stands of Pinus sylvestris and Quercus pyrenaica. Annals of Forest Science, 66, 1-11.

Rothe, A., \& Binkley, D. (2001). Nutritional interactions in mixed species forests: A synthesis. Canadian Journal of Forest Research, 31, 1855-1870.

Toigo, M., Vallet, P., Tuilleras, V., Lebourgeois, F., Rozenberg, P., Perret, B., Courbaud, S., \& Perot, S. (2015). Species mixture increases the effect of drought on tree ring density, but not on ring width, in Quercus petraeaPinus sylvestris stands. Forest Ecology and Management, 135, 73-82.

Tsvetkova, N. M., Pakhomov, O. Y., Serdyuk, S. M., \& Yakyba, M. S. (2016). Biologichne riznomanittja Ukrajiny. Dnipropetrovs'ka oblast'. Grunty. Meta- 
ly u gruntah [Biological diversity of Ukraine. The Dnipropetrovsk region. Soils. Metalls in the soils]. Lira, Dnipropetrovsk (in Ukrainian).

Shanin, V., Komarov, A., \& Mäkipää, R. (2014). Tree species composition affects productivity and carbon dynamics of different site types in boreal forests. European Journal of Forest Research, 133(2), 273-286.

Schmid, I., \& Kazda, M. (2002). Root distribution of Norway spruce in monospecific and mixed stands on different soils. Forest Ecology and Management, 159, 37-47.
Sidel'nik, N. A. (1977). Osnovnye principy sozdanija lesnyh kul'tur v uslovijah Stepi [Basic principles of creating the forest cultures in conditions Steppe]. Voprosy Stepnogo Lesovedenija i Ohrany Prirody, 69-74 (in Russian).

Webster, C. R., \& Lorimer, C. G. (2003). Comparative growing space efficiency of four tree species in mixed conifer-hardwood forests. Forest Ecology and Management, 177, 361-377. 